\title{
Low FT4 Concentrations around the Start of Recombinant Human Growth Hormone Treatment: Predictor of Congenital Structural Hypothalamic-Pituitary Abnormalities?
}

\author{
Laura van lersel ${ }^{a, b}$ Hanneke M. van Santen ${ }^{b}$ Gladys R.J. Zandwijken ${ }^{c}$ \\ Nitash Zwaveling-Soonawala a Anita C.S. Hokken-Koelegac, d \\ A.S. Paul van Trotsenburga \\ a'Department of Pediatric Endocrinology, Emma Children's Hospital, Academic Medical Center, University of \\ Amsterdam, Amsterdam, The Netherlands; ${ }^{b}$ Department of Pediatric Endocrinology, Wilhelmina Children's Hospital, \\ University Medical Center Utrecht, Utrecht, The Netherlands; ' ${ }^{C}$ Dutch Growth Research Foundation, Rotterdam, \\ The Netherlands; ${ }^{d}$ Department of Pediatrics, Division of Endocrinology, Erasmus University Medical Center, \\ Rotterdam, The Netherlands
}

\section{Keywords}

Central hypothyroidism · Nonacquired growth

hormone deficiency. Growth hormone treatment .

Hypothalamic-pituitary abnormalities · Neonatal screening

\begin{abstract}
Background: Growth hormone (GH) treatment may unmask central hypothyroidism (CeH). This was first observed in children with GH deficiency (GHD), later also in adults with GHD due to acquired "organic" pituitary disease. We hypothesized that newly diagnosed $\mathrm{CeH}$ in children after starting GH treatment for nonacquired, apparent isolated GHD points to congenital "organic" pituitary disease. Methods: Nationwide, retrospective cohort study including all children with nonacquired GHD between 2001 and 2011 in The Netherlands. The prevalence of $\mathrm{CeH}$, hypothalamic-pituitary (HP) abnormalities, and neonatal congenital hypothyroidism screening results were evaluated. Results: Twenty-three (6.3\%) of 367 children with apparent isolated GHD were prescribed LT4 for presumed $\mathrm{CeH}$ within 2 years after starting $\mathrm{GH}$ treatment.
\end{abstract}

Similarly to children already diagnosed with multiple pituitary hormone deficiency, $75 \%$ of these 23 had structural HP abnormalities. In children not prescribed LT4, low pre- or post-GH treatment FT4 concentrations were also associated with structural HP abnormalities. Neonatal screening results of only 4 of the 23 children could be retrieved. Conclusion: In children with nonacquired, apparent isolated GHD, a diagnosis of $\mathrm{CeH}$ after, or a low FT4 concentration around the start of GH treatment, is associated with congenital structural HP abnormalities, i.e., "organic" pituitary disease. Neonatal values could not be judged reliably.

(c) 2018 The Author(s)
Published by S. Karger AG, Basel

\section{Introduction}

Since its introduction in the mid-1980s, treatment with human recombinant growth hormone $(\mathrm{GH})$ has become common practice in the fields of pediatric and adult endocrinology [1-3]. The influence of GH administration on the hypothalamic-pituitary-thyroid axis is well

\begin{tabular}{ll}
\hline KARGER & $\begin{array}{l}\text { C } 2018 \text { The Author(s) } \\
\text { Published by S. Karger AG, Basel }\end{array}$ \\
E-Mail karger@karger.com & This article is licensed under the Creative Commons Attribution- \\
www.karger.com/hrp & $\begin{array}{l}\text { NonCommercial-NoDerivatives 4.0 International License (CC BY- } \\
\text { NC-ND) (http://www.karger.com/Services/OpenAccessLicense). } \\
\text { Usage and distribution for commercial purposes as well as any dis- } \\
\text { tribution of modified material requires written permission. }\end{array}$
\end{tabular}

A.S. Paul van Trotsenburg, MD, $\mathrm{PhD}$

Department of Pediatric Endocrinology, Emma Children's Hospital

Academic Medical Center, PO Box 22660

NL-1100DD Amsterdam (The Netherlands)

E-Mail a.s.vantrotsenburg@amc.uva.nl 
recognized [4]. In non-GH-deficient individuals, GH administration may result in slightly lower plasma or serum-free thyroxine (FT4) concentrations in combination with higher triiodothyronine (T3) concentrations and almost unchanged thyroid-stimulating hormone (TSH) concentrations [5-7]. These changes in thyroid hormone levels are usually temporary and are thought to be caused by increased T4 to T3 conversion and inhibition of TSH secretion [5]. However, often FT4, T3, and TSH do not show any changes $[8,9]$.

In contrast to non-GH-deficient individuals, in patients with $\mathrm{GH}$ deficiency (GHD) changes are often more pronounced and in the last few decades, it has become clear that GH treatment in patients with GHD may unmask central hypothyroidism $(\mathrm{CeH}) . \mathrm{CeH}$ is defined as an FT4 concentration below the age-specific reference interval, in combination with a low, normal or slightly elevated TSH concentration [10]. Unmasking refers to a decrease in FT4 from within the reference range, to below the reference range. This was first observed in children with an initial diagnosis of isolated GHD, who were subsequently reclassified as having multiple (or combined) pituitary hormone deficiency (MPHD) [11]. Later on, it was also reported in adults, especially in those with acquired GHD due to "organic" pituitary disease, i.e., trauma, tumor or after pituitary surgery [12-14].

In the past 15 years, we have also encountered several children with $\mathrm{CeH}$ shortly after starting $\mathrm{GH}$ treatment for apparent isolated GHD. Additional testing revealed central adrenal insufficiency in a number of these patients. All patients had structural hypothalamic-pituitary (HP) abnormalities mainly consisting of an ectopic posterior pituitary and/or pituitary hypoplasia. In a recent MRI study in early childhood GHD, it was reported that all children with GHD as part of MPHD had complex pituitary defects (i.e., ectopic posterior pituitary, with or without pituitary hypoplasia, and pituitary stalk or midline abnormalities). In contrast, most of the children with isolated GHD had a normal pituitary anatomy or only isolated pituitary hypoplasia [15]. Nowadays, most pediatric endocrinologists perform additional pituitary function tests and MRI of the HP region in children diagnosed with GHD. Since MRI is usually not possible in young children without the use of general anesthesia, imaging is often postponed until an older age, especially when other pituitary deficiencies seem to be absent. Since the gonadal axis cannot be reliably tested beyond the first months of life, and the adrenal axis requires dynamic testing, the decision to perform MRI under general anesthesia may be solely guided by the presence of $\mathrm{CeH}$. This raises the question whether low FT4 concentrations and/or a diagnosis of $\mathrm{CeH}$ at initiation of $\mathrm{GH}$ treatment for apparent GHD indicates congenital pituitary malformation.

In The Netherlands, each year 8-10 children with $\mathrm{CeH}$ are detected in the neonatal screening program for congenital hypothyroidism $(\mathrm{CH}$; Dutch incidence: approximately 1 in 16,000) [16]. Approximately 75\% of these children have congenital MPHD, usually including GHD and most of these children have pituitary malformations $[16,17]$. These pituitary malformations are similar to those seen in children initially presenting with isolated GHD which turns out to be part of MPHD including $\mathrm{CeH}$. These children apparently had not been detected in the Dutch neonatal screening program for $\mathrm{CH}$. We hypothesized that their neonatal thyroid hormone concentrations may be at the lower limit of the reference range but not low enough to be detected by neonatal screening.

To study the occurrence of $\mathrm{CeH}$ after initiation of $\mathrm{GH}$ treatment in children with congenital GHD, we conducted a nationwide, retrospective cohort study including all children with congenital GHD diagnosed between January 2001 and January 2011 in The Netherlands. To identify MPHD, we studied the presence of structural and/or functional HP abnormalities. In addition, we attempted to retrieve neonatal $\mathrm{CH}$ screening results.

\section{Subjects and Methods}

\section{Patients}

All children diagnosed with congenital GHD between January 2001 and January 2011 in the Netherlands, and younger than 18 years at the initiation of GH treatment, were eligible for the study. Patients were retrieved from the database of the Dutch Growth Research Foundation (DGRF). GHD was defined as a maximal plasma GH concentration $\leq 20 \mathrm{mIU} / \mathrm{L}$ in two $\mathrm{GH}$ stimulation tests combined with a sex- and age-specific serum IGF-1 concentration $<0 \mathrm{SD}$, or a maximal $\mathrm{GH} \leq 30 \mathrm{mIU} / \mathrm{L}$ in combination with an IGF-1 <-2 SD (most Dutch laboratories report GH concentrations in milli-international units/liter; to convert to microgram/liter, divided by 3) [18]. Exclusion criteria were acquired GHD (brain tumor, cranial or total body irradiation, or traumatic brain injury), possible (partial) GH resistance, and GH treatment for indications other than GHD. Children treated with levothyroxine (LT4), hydrocortisone, sex steroids or desmopressin prior to the start of GH treatment were classified as having MPHD (two or more pituitary deficiencies). The occurrence of $\mathrm{CeH}$ after the initiation of $\mathrm{GH}$ treatment was defined as a low plasma FT4 concentration in the presence of an inappropriately low, normal or mildly elevated TSH, for which LT4 treatment had been started by the child's doctor [19]. In The Netherlands, the lower limit of the adult reference interval of most FT4 assays is between 8 and $12 \mathrm{pmol} / \mathrm{L}$, with an average of around $10 \mathrm{pmol} / \mathrm{L}$; the average upper limit is $23 \mathrm{pmol} / \mathrm{L}$ (personal communications). The lower limit of most TSH assays 


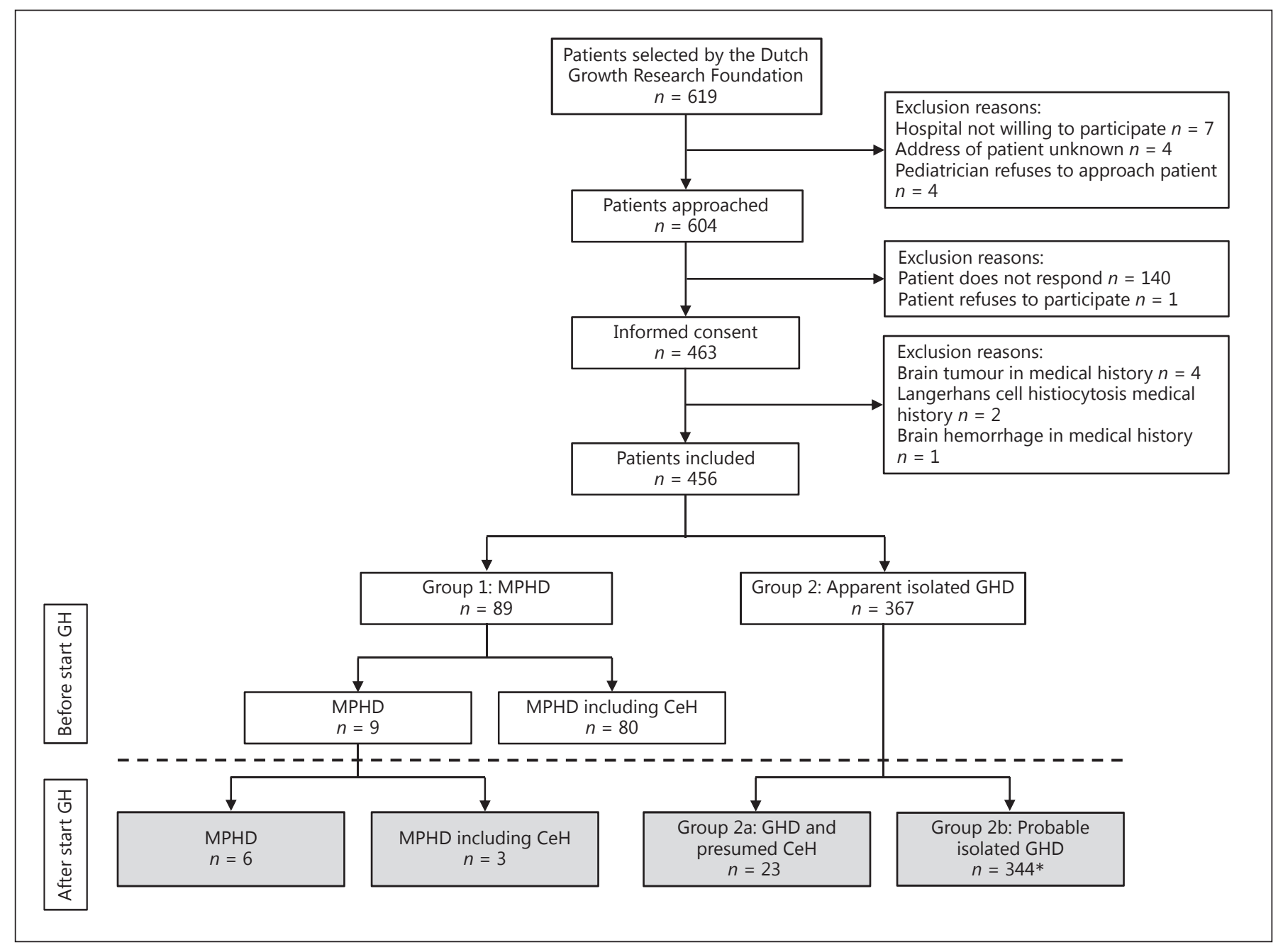

Fig. 1. Selection of patients. White boxes represent the classification of patients at the start of growth hormone treatment; gray boxes represent the classification of patients 2 years after the start of growth hormone treatment. $\mathrm{CeH}$, central hypothyroidism; GHD, growth hormone deficiency; MPHD, multiple pituitary hor-

is between 0.3 and $0.5 \mathrm{mIU} / \mathrm{L}$, with an average of around 0.4 $\mathrm{mIU} / \mathrm{L}$; the highest reported upper limit is $5.0 \mathrm{mIU} / \mathrm{L}$. Since innocent and transitory changes in thyroid hormone levels after the initiation of GH treatment usually resolve within 1-2 years, we set the time window for the diagnosis of $\mathrm{CeH}$ to be made at 2 years after the start of GH treatment [20].

Data were extracted from the children's hospital records and DGRF database files, and were cross-checked with data stored by the National Institute for Public Health and the Environment (RIVM-DVP, the organization responsible for the Dutch neonatal screening). MRI reports were retrospectively retrieved and classified as either "normal" or "abnormal" (reported as ectopic posterior pituitary; absent or thin pituitary stalk; pituitary hypoplasia; empty sella). In addition, parents were asked to participate in a structured telephonic interview to collect information on clinical mone deficiency. ${ }^{*}$ Two patients with probable isolated GHD were prescribed thyroxine for potential primary hypothyroidism after the start of GH treatment (pretreatment FT4 and TSH concentrations: $15.0 \mathrm{pmol} / \mathrm{L}$ and $5.6 \mathrm{mIU} / \mathrm{L}$, and $14.1 \mathrm{pmol} / \mathrm{L}$ and 9.83 $\mathrm{mIU} / \mathrm{L}$, respectively). factors influencing neonatal thyroid function. To keep the investigators blinded, with a few exceptions, interviews were performed before retrieval of data from hospital records, database files, and neonatal screening results. According to the Dutch neonatal screening definitions, children were classified as "premature" if gestational age was $<36$ weeks in combination with a birth weight $<2.5 \mathrm{~kg}$. "Non-thyroidal illness" was suspected when the interview revealed birth asphyxia (5 min Apgar score $<7$ ), use of intravenous antibiotics (for probable perinatal infection), weight loss of $10 \%$ or more (often resulting from feeding problems) or gastrointestinal surgery preceding the neonatal screening.

The Medical Ethics Committee of the Academic Medical Center, the Dutch national GH advisory board and the RIVM approved the study. Written informed consent was obtained from all children and their parents. 
Table 1. Baseline characteristics of the 456 patients at the start of GH treatment

\begin{tabular}{|c|c|c|c|}
\hline Characteristics & $\begin{array}{l}\text { Group } 1(n=89) \text {; GHD } \\
\text { probably within the } \\
\text { framework of congenital } \\
\text { MPHD }^{\mathrm{a}}\end{array}$ & \multicolumn{2}{|c|}{ Group $2(n=367)$; apparent isolated GHD } \\
\hline Gender (male), $n(\%)$ & $63(70.8)$ & $15(65.2)$ & $230(66.9)$ \\
\hline Gestational age, weeks & $39.0(26.1$ to 42.7$)$ & $40.0(30.0$ to 42.0$)$ & $40.0(25.0$ to 43.0$)$ \\
\hline Age, years & $3.90(0.17 \text { to } 16.11)^{\mathrm{c}}$ & $4.36(1.89$ to 14.34$)$ & $5.62(0.54$ to 15.68$)$ \\
\hline Height SDS & $-3.00(-6.89$ to -0.03$)$ & $-2.89(-4.48$ to -1.72$)$ & $-2.92(-6.69$ to -0.72$)$ \\
\hline Bone age delay, years & $-1.3(-6.6$ to 1,0$)$ & $-1.4(-4.0$ to 0.7$)$ & $-1.2(-11.4$ to 0.6$)$ \\
\hline $\begin{array}{l}\text { Maximum stimulated } \mathrm{GH} \\
\text { concentration, } \mathrm{mIU} / \mathrm{L}^{\mathrm{d}}\end{array}$ & $8.6(0.1$ to 34.2$)$ & $13.0(3.2$ to 29.9$)$ & $16.1(1.0-61.6)^{\mathrm{e}}$ \\
\hline $\begin{array}{l}\text { Thyroid function parameters } \\
\text { FT4, pmol/L } \\
\text { TSH, mIU/L }\end{array}$ & & $\begin{array}{l}\text { After the start of GH treatment } \\
9.9(6.6 \text { to } 12.0)^{\mathrm{h}} \\
1.98(0.12 \text { to } 3.30)\end{array}$ & $\begin{array}{l}6 \text { months (range } 4-8) \text { after the } \\
\text { start of GH treatment } \\
14.0(8.2-25.0) \\
2.60(0.93-7.00)\end{array}$ \\
\hline Thyroid function parameters & & $\begin{array}{l}\text { After the start of LT4 treatment } \\
16.1(12.0 \text { to } 20.1) \\
0.39(0.01 \text { to } 3.30)\end{array}$ & $\begin{array}{l}12 \text { months (range } 9-13) \text { after the } \\
\text { start of GH treatment } \\
14.8(8.1-22.8) \\
2.44(0.52-7.75)\end{array}$ \\
\hline $\begin{array}{l}\text { MRI results, } n \\
\text { Total available MRI results } \\
\text { Normal MRI result } \\
\text { Abnormal MRI result }{ }^{\mathrm{i}}\end{array}$ & $\begin{array}{l}75 \\
19 \\
56\end{array}$ & $\begin{array}{l}21 \\
5 \\
16\end{array}$ & $\begin{array}{l}213 \\
150 \\
63\end{array}$ \\
\hline
\end{tabular}

Bone age delay, delay with respect to calendar age; GHD, growth hormone deficiency; MPHD, multiple (or combined) pituitary hormone deficiency; $\mathrm{CeH}$, central hypothyroidism; SDS, standard deviation. All values are median (min. to max.), except where indicated otherwise. ${ }^{\text {a }}$ Of the patients with MPHD, GHD was combined with central hypothyroidism only (CeH) in $n=40$, with central adrenal insufficiency only (CeA) in $n=4$, with central (or hypogonadotropic) hypogonadism only (CeHy) in $n=2$, or with diabetes insipidus only (CeDI) in $n=2$; in the other patients with MPHD, GHD was combined with both $\mathrm{CeH}$ and CeA in $n=36$, or with both CeH and CeDI in $n=1 ; 4$ patients had dysfunction of $>3$ pituitary axes: $\mathrm{CeH}+\mathrm{CeA}+\mathrm{CeHy}$ in $n=2$, and $\mathrm{CeH}+\mathrm{CeA}+\mathrm{CeDI}$ in $n=2$. ${ }^{\mathrm{b}}$ Two patients with probable isolated GHD were prescribed thyroxine for potential primary hypothyroidism after the start of GH treatment (pretreatment FT4 and TSH concentrations: $15.0 \mathrm{pmol} / \mathrm{L}$ and $5.6 \mathrm{mIU} / \mathrm{L}$, and $14.1 \mathrm{pmol} / \mathrm{L}$ and $9.83 \mathrm{mIU} / \mathrm{L}$, respectively). ${ }^{c}$ Group 1 vs. groups $2 \mathrm{a}$ and $2 \mathrm{~b}, p<0.05 .{ }^{\mathrm{d}}$ In 6 patients, maximum stimulated GH concentrations were not available, because the diagnosis GHD was based on clinical symptoms $(n=2)$, or GH was only measured during hypoglycemia $(n=2)$ or randomly in neonates $(n=2)$. ${ }^{\mathrm{e}}$ Group $2 \mathrm{~b}$ vs. groups 1 and $2 \mathrm{a}, p<0.05 .{ }^{\mathrm{f}}$ The lower limits of most FT4 assays are between 8 and $12 \mathrm{pmol} / \mathrm{L}$, with an average around $10 \mathrm{pmol} / \mathrm{L}$. The average upper limit is $23 \mathrm{pmol} / \mathrm{L}$ The lower limits of most TSH assays are between 0.3 and $0.5 \mathrm{mIU} / \mathrm{L}$, with an average around $0.4 \mathrm{mIU} / \mathrm{L}$. The highest used upper limit is $5.0 \mathrm{mIU} / \mathrm{L} .{ }^{\mathrm{g}}$ Group $2 \mathrm{a}$ vs. group $2 \mathrm{~b}, p<0.001 .{ }^{\mathrm{h}}$ Difference in FT4 concentration before and after the start of GH treatment within group 2a, $p<0.001 .{ }^{\mathrm{i}}$ Abnormal MRI refers to one or more of the following congenital abnormalities: ectopic posterior pituitary; absent or thin pituitary stalk; pituitary hypoplasia; empty sella.

\section{Neonatal Screening Results}

The Dutch neonatal CH screening is primarily (total) T4 based. TSH is measured in the $20 \%$ lowest T4 concentrations with an additional T4-binding globulin (TBG) measurement in the $5 \%$ lowest T4 concentrations [21]. All screening laboratories use the same $\mathrm{T} 4$, TSH, and TBG assays. Quarterly nationwide quality controls guarantee high reproducibility and comparability. Since screening results were stored in a single national RIVM database from 2002 onward, we were not able to retrieve normal results of children born before that year. However, we were able to retrieve abnormal screening results by searching paper archives of regional screening centers. 


\section{Statistical Analyses}

Patients were divided into two groups: group 1 consisting of patients with MPHD and group 2 consisting of patients with apparent isolated GHD (i.e., no treatment for other pituitary deficiencies at the start of GH treatment). Group 2 was further divided into patients who were prescribed LT4 for presumed $\mathrm{CeH}$ within 2 years after starting GH treatment (group 2a), and those who were not (group 2b).

Data are presented as median (min. to max.). Nonnormally distributed data in more than two categories were tested for significance by the Kruskall-Wallis test for nonparametric measurements. Two categories were compared with the Mann-Whitney $U$ test. Categorical data were compared using the $\chi^{2}$ test. The paired $t$ test was used to compare differences within groups during treatment in normally distributed data and the Wilcoxon signed rank test in nonnormally distributed data. A value of $p<0.05$ was considered statistically significant. Data were analyzed using SPSS version 22 for Windows (IBM SPSS System Inc., Chicago, IL, USA).

\section{Results}

\section{Patients}

In the DGRF database, inclusion criteria were met by 619 children of whom 604 could be contacted by their participating pediatricians (endocrinologists). Four hundred and sixty-three children and parents agreed to participate, but 7 children were excluded due to previously unnoticed acquired GHD, resulting in 456 children (Fig. 1).

\section{Baseline Characteristics, and Thyroid Function before and after Starting GH Treatment}

Eighty-nine of the 456 included patients were diagnosed with MPHD (group 1), and 367 with apparent isolated GHD (group 2) before GH treatment. Twenty-three children in group $2(6.3 \%)$ were prescribed LT4 treatment for presumed $\mathrm{CeH}$ diagnosed within 2 years after the initiation of GH treatment (after a median of 0.6 years, range 0.1-1.9; group 2a). Three hundred and forty-two of the remaining 344 children (group $2 \mathrm{~b}$ ) were judged as having

Fig. 2. FT4 and TSH concentrations before $(\mathbf{a}, \mathbf{b})$ and after the start of growth hormone treatment (c-f), in the children who were (a, $\mathbf{c}, \mathbf{e})$ and were not $(\mathbf{b}, \mathbf{d}, \mathbf{f})$ treated with levothyroxine. The circles in $\mathbf{a}, \mathbf{c}$, and e represent the children who were diagnosed with (presumed) central hypothyroidism after the start of growth hormone treatment. a Before the start of growth hormone treatment. c After the start of growth hormone treatment, but before the start of levothyroxine treatment. e After the start of levothyroxine treatment. The circles in $\mathbf{b}, \mathbf{d}$, and $\mathbf{f}$ represent the children whose thyroid function was judged as "normal" before (b) and after (d) the a normal thyroid function, while 2 children were prescribed LT4 for presumed mild primary hypothyroidism. In 80 of the 89 children in group 1 - the MPHD group -, LT4 treatment was already started before GH treatment, in 3 other children LT4 was started after initiation of GH treatment. Table 1 shows the baseline characteristics of the children in groups $1,2 \mathrm{a}$, and $2 \mathrm{~b}$. Compared to groups $2 \mathrm{a}$ and $2 \mathrm{~b}$, the children in group 1 were significantly younger at the start of GH treatment ( 3.90 vs. 4.36 and 5.62 years, respectively). Maximum stimulated $\mathrm{GH}$ concentrations were significantly lower in groups 1 and 2a compared to group $2 \mathrm{~b}$ (8.6 vs. 13.0 and $16.1 \mathrm{mIU} / \mathrm{L}$, respectively).

Before starting GH treatment, the median plasma FT4 concentration of the children in group $2 \mathrm{a}$ was significantly lower than in group $2 \mathrm{~b}$ (12.3 vs. $15.1 \mathrm{pmol} / \mathrm{L}$, respectively; $p<0.001$ ), while the median TSH concentrations were similar (online suppl. Table 1; for all online suppl. material, see www.karger.com/doi/10.1159/000486033). After starting GH treatment, the median plasma FT4 concentration in group $2 \mathrm{a}$ decreased to $9.9 \mathrm{pmol} / \mathrm{L}$. After the start of LT4 treatment, median FT4 increased and TSH decreased from 1.98 to $0.39 \mathrm{mIU} / \mathrm{L}$. In group $2 \mathrm{~b}$, the children with presumed "normal" pituitary function, FT4 decreased from $15.1 \mathrm{pmol} / \mathrm{L}$ to $14.0 \mathrm{pmol} / \mathrm{L}$, but within 1 year FT4 spontaneously increased to $14.8 \mathrm{pmol} / \mathrm{L}$. TSH did not change significantly.

Figure 2 shows scatterplots of the FT4 and TSH concentrations of the children in groups $2 \mathrm{a}$ and $2 \mathrm{~b}$ before and after initiation of GH treatment. The third time point in these scatterplots represents the FT4 and TSH concentrations on LT4 treatment in group 2a or after 1 year of GH treatment in group $2 \mathrm{~b}$. An intriguing observation is that a number of children in group $2 b-$ i.e., the children judged as having a normal thyroid function - had a low or low normal FT4 concentration before and after initiation of GH treatment, and also later on. Twelve of them were still prescribed LT4 more than 2 years after initiation of GH treatment (after a median of 5.1 years, range start of growth hormone treatment. $\mathbf{f}$ Their thyroid function approximately 1 year later. The vertical and horizontal lines represent the median FT4 and TSH concentrations, respectively. The vertical and horizontal dashed lines represent the lower and upper limits of the adult FT4 and TSH reference intervals. The lower limits of most FT4 assays are between 8 and $12 \mathrm{pmol} / \mathrm{L}$, with an average around $10 \mathrm{pmol} / \mathrm{L}$. The average upper limit is $23 \mathrm{pmol} / \mathrm{L}$. The lower limits of most TSH assays are between 0.3 and $0.5 \mathrm{mIU} / \mathrm{L}$, with an average around $0.4 \mathrm{mIU} / \mathrm{L}$. The highest used upper limit is $5.0 \mathrm{mIU} / \mathrm{L}$.

(For figure see next page.) 

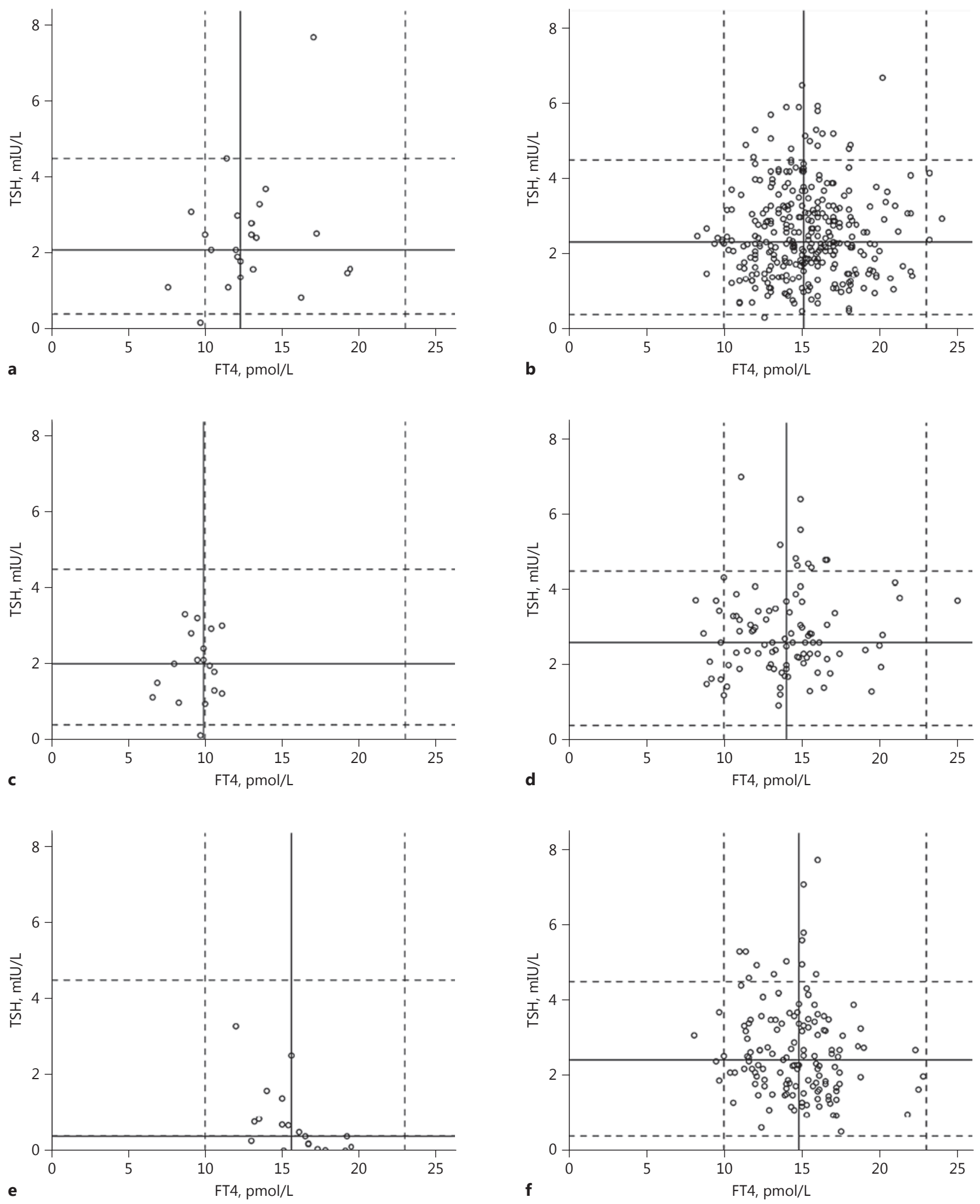
Table 2. Neonatal screening results of the children with multiple pituitary hormone deficiency versus the children with GH deficiency and newly diagnosed central hypothyroidism, and those with probable isolated GH deficiency at the start of GH treatment

\begin{tabular}{|c|c|c|c|c|c|c|c|c|c|c|c|c|}
\hline & $n$ & $\begin{array}{l}\text { T4 (SD } \\
\text { score) }\end{array}$ & Min. to max. & $n$ & $\begin{array}{l}\text { TSH, } \\
\text { mIU/L }\end{array}$ & Min. to max. & $n$ & $\begin{array}{l}\mathrm{TBG}, \\
\mathrm{nmol} / \mathrm{L}\end{array}$ & Min. to max. & $n$ & $\begin{array}{l}\mathrm{T} 4 / \mathrm{TBG} \\
\text { ratio }\end{array}$ & Min. to max. \\
\hline \multicolumn{13}{|c|}{ Neonatal screening results, minus excluded results ${ }^{\mathrm{a}}$} \\
\hline Group 1 & 26 & -2.2 & -4.3 to 1.4 & 20 & 1.50 & 0.50 to 4.50 & 18 & 195.5 & 113.0 to 345.0 & 18 & 13.0 & 5.8 to 21.3 \\
\hline Group 2a & 4 & -1.9 & -3.0 to -0.4 & 3 & 1.50 & 1.50 to 2.00 & 3 & 160.5 & 107.5 to 174.0 & 3 & 19.6 & 19.4 to 19.6 \\
\hline \multirow[t]{2}{*}{ Group 2b } & 126 & $-0.5^{\mathrm{b}}$ & -2.9 to 2.3 & 34 & 1.50 & 0.50 to 5.50 & 10 & 166.0 & 105.0 to 224.0 & 10 & 19.8 & 12.6 to 29.6 \\
\hline & $\begin{array}{l}\mathrm{T} 4 \text { (SD } \\
\text { score) }\end{array}$ & $\begin{array}{l}\text { TSH, } \\
\mathrm{mIU} / \mathrm{L}\end{array}$ & TBG, nmol/L & $\begin{array}{l}\mathrm{T} 4 / \mathrm{TBG} \\
\text { ratio }\end{array}$ & Result & & & & & & & \\
\hline
\end{tabular}

Individual neonatal screening results group $2 a$

Subject

$\begin{array}{cccccl}6^{\mathrm{c}} & -3.8 & 4.00 & 71.5 & 18.2 & \begin{array}{l}\text { Negative } \\ 7\end{array} \\ 16^{\mathrm{c}} & -0.4 & & & & \text { Negative } \\ 17^{\mathrm{d}} & -1.8 & 1.00 & 184.0 & 17.9 & \text { Negative } \\ 19 & -3.0 & 1.50 & 107.5 & 19.6 & \text { Positive } \\ 20 & -1.7 & 1.50 & 174.0 & 19.6 & \text { Negative } \\ & -2.0 & 2.00 & 160.5 & 19.4 & \text { Negative }\end{array}$

a Sixty neonatal screening results were excluded from the analysis because of prematurity $(n=30)$ or probable nonthyroidal illness $(n=30)$. Another 9 results were excluded because of missing perinatal data. ${ }^{\mathrm{b}}$ Group $2 \mathrm{~b}$ vs. groups 1 and $2 \mathrm{a}$ : $p<0.05 .{ }^{\mathrm{c}}$ Excluded neonatal screening results in group 2a: subject 6 , for prematurity (gestational age 30 weeks, birth weight $810 \mathrm{~g}$ ); subject 16, for probable nonthyroidal illness (breech delivery, Apgar score unknown, transfer to university medical center for unexplained low heart rate). ${ }^{\mathrm{d}}$ Abnormal first neonatal screening result (very low T4 SD score); patient was referred to a pediatrician, but not treated; FT4 concentration could not be retrieved. For all measurements, medians and means were approximately similar, except for the TSH concentration, which is not distributed normally.

2.9-9.8). Based on the assumption that these children may very well have - at that time still undiagnosed - $\mathrm{CeH}$, and that structural abnormalities of the HP region may support this diagnosis, we compared the MRI results of the children in groups 1, 2a, and 2b, and we analyzed HP MRI results of the children in group $2 \mathrm{~b}$ in relation to FT4 at the three time points.

\section{MRI Results}

HP MRI results of 309 of the 456 included patients were available. Sixteen of 21 (76.2\%) MRI studies of patients in group $2 \mathrm{a}$ showed congenital abnormalities, similar to the percentage of the children in group 1 (abnormalities in 56 of $75[74.7 \%]$ ), but clearly higher than the percentage in group $2 \mathrm{~b}$ (abnormalities in 63 of 213 [29.6\%]). Sixteen of the 344 children in group $2 \mathrm{~b}$ had FT4 concentrations $<10 \mathrm{pmol} / \mathrm{L}$ before or at least at one measurement after initiation of GH treatment. In 8 of these 16 cases, MRI results were available and showed congenital abnormalities in 6 cases (75\%). When this analysis was repeated in children with a lowest FT4 concentration of $10-11 \mathrm{pmol} / \mathrm{L}$, the percentage was $57 \%$ (4 of 7). In children with a lowest FT4 concentration of 11-12 pmol/L, this was $25 \%$ (5 of 20 ). In children with a lowest FT4 concentration of $12-13,13-14$ and $\geq 14$ $\mathrm{pmol} / \mathrm{L}$, the percentages were $28.6,26.7$, and $26.8 \%$. In 8 of the 12 children who were prescribed LT4 more than
2 years after the initiation of GH treatment, MRI studies were available, with congenital abnormalities in 5 cases $(62.5 \%)$.

\section{Neonatal Screening Results}

Parents of 400 children were interviewed, and neonatal $\mathrm{CH}$ screening results of 225 could be retrieved. Sixty screening results were excluded from analysis because of prematurity $(n=30)$ or probable nonthyroidal illness $(n=30)$. Another 9 were excluded because of missing perinatal data. In total, screening results of 156 children were available for analysis. Screening results of only 4 children in group $2 \mathrm{a}$ were retrieved. Their T4 concentrations were clearly lower than in group $2 b$, but comparable to group 1 (median T4 SD scores -1.9 [group 2a, $n=4$ ], -0.5 [group $2 \mathrm{~b}, n=126$ ], and -2.2 [group $1, n=26$ ], respectively; $p<0.05$ for group $2 \mathrm{~b}$ vs. groups 1 and $2 \mathrm{a}$ ) (Table 2). TSH concentrations were similar.

\section{Adrenal Axis Testing Results}

Assessment of the HP adrenal axis was performed in 11 of the 23 children in group $2 \mathrm{a}$ after initiation of GH treatment. In 6 patients, a classic $(250 \mu \mathrm{g}) \mathrm{ACTH}$ test was performed, in 2 a low-dose $(1 \mu \mathrm{g})$ ACTH test, and in 1 a morning cortisol measurement was used to evaluate the HP adrenal axis. In 2 other patients, the mode of testing or results could not be retrieved. However, in these 2 pa- 
tients the medical chart mentioned the prescription of cortisol treatment for insufficient ACTH reserve. Six of these 11 patients were subsequently treated with hydrocortisone, 3 after and 3 before initiation of LT4 treatment. Two children were prescribed hydrocortisone use during stress only. In the 8 patients with an abnormal HP adrenal axis test result and available MRI result, 5 were abnormal (ectopic posterior pituitary, in combination with pituitary hypoplasia $[n=4]$ or a thin pituitary stalk in combination with pituitary hypoplasia $[n=1])$. All 3 patients with a normal ACTH test result had pituitary hypoplasia.

\section{Discussion}

In this large Dutch cohort of children treated with GH for apparent isolated GHD, 23 children (6.3\%) were prescribed LT4 treatment for presumed $\mathrm{CeH}$ within 2 years after initiation of GH treatment. Similar to children already diagnosed with (congenital) MPHD before starting GH treatment, approximately three-quarter of these children had congenital structural HP abnormalities. In retrospect, 3 of these patients had FT4 concentrations just below the reference range interval before the initiation of GH treatment, but were prescribed LT4 only after further decrease of FT4 concentrations. In children with apparent isolated GHD, not prescribed LT4 treatment after initiation of GH treatment, a relationship was found between FT4 concentrations and the presence of anatomic pituitary abnormalities. In these children, the lower the pre- or post-GH treatment FT4 concentrations were, the higher the chance that MRI revealed congenital pituitary malformations. In children with the lowest FT4 concentrations (one or more times $<10 \mathrm{pmol} / \mathrm{L}$ ), the percentage of pituitary abnormalities was even similar to that in children with MPHD (75\%). If all children with apparent isolated GHD, and a low FT4 ( $<10 \mathrm{pmol} / \mathrm{L})$, and abnormal MRI are considered to have $\mathrm{CeH}$, the percentage of unmasked $\mathrm{CeH}$ around the initiation of $\mathrm{GH}$ treatment increases to $7.9 \%(23+6=29 ; 29$ of $367=7.9 \%)$. Several children with newly diagnosed $\mathrm{CeH}$ were also diagnosed with central adrenal insufficiency, and were started on hydrocortisone treatment or were prescribed hydrocortisone during periods of stress or illness. Unfortunately, neonatal $\mathrm{CH}$ screening results were available for only 4 of the 23 children prescribed LT4. These 4 children had lower neonatal screening T4 concentrations, similar to children who were already diagnosed with MPHD before starting GH treatment. This supports our hypothesis that a (too) low FT4 around the initiation of GH treatment in

Isolated GH deficiency and Low FT4

Concentrations a child with apparent isolated GHD is a very strong predictor of the presence of MPHD resulting from congenital, structural pituitary abnormalities. The finding that the neonatal $\mathrm{CH}$ screening results available in the few children with presumed $\mathrm{CeH}$ were lower than average suggests that the $\mathrm{CeH}$, although probably mild, may have been present from birth onwards. However, this observation needs to be validated in a larger group of patients.

This is not the first study to demonstrate lower thyroid hormone concentrations after initiation of $\mathrm{GH}$ treatment in children with GHD suggestive of $\mathrm{CeH}[11,22,23]$. However, in all previous studies the children showing this phenomenon were already diagnosed with acquired organic pituitary disease or congenital MPHD. The same applies to studies in adults, in which GH treatment was found to unmask $\mathrm{CeH}$ in patients with known acquired organic pituitary disease [4]. Our study is the first to demonstrate this phenomenon in children with presumed isolated GHD; the low FT4 concentrations were the first clue for additional functional and/or structural pituitary abnormalities. As already mentioned in the introduction, Pampanini et al. [15] recently described brain MRI findings in 68 children diagnosed with GHD before the age of 4 years. All 31 children diagnosed with MPHD had complex pituitary defects, while most of the 37 children diagnosed with isolated GHD only showed isolated pituitary hypoplasia or even a normal pituitary gland. Children with MPHD were diagnosed at a younger age than children with isolated GHD. With respect to the presence or absence of structural HP abnormalities, the results of our study are in line with these results. The children in our study diagnosed with MPHD before the initiation of GH treatment, and the children diagnosed with $\mathrm{CeH}$ after the initiation of GH treatment, had a higher percentage of "complex defects" than the children diagnosed with probably isolated GHD.

The Dutch neonatal CH screening consists of a threestep "T4+TSH+TBG" approach, enabling calculation of the so-called "T4/TBG ratio" [16]. The 29 children in this study with (probable) $\mathrm{CeH}$ and not detected by neonatal screening had a $\mathrm{T} 4$ concentration, or a T4/TBG ratio above the screening cutoffs. If these 29 children really had (mild) congenital $\mathrm{CeH}$, this would raise the Dutch prevalence from 1 case per 16,404 to approximately 1 case per 13,211 [16]. Increasing neonatal screening cutoffs would probably enable the detection of these mild cases of $\mathrm{CeH}$ but would result in an increase in false-positive test results.

Genetic results were available in 2 of the 23 children treated with LT4 after initiation of GH treatment. One 
child had a mutation in $I G S F 1$, another in POU1F1, both well-known genetic causes of congenital $\mathrm{CeH}$ [24-27]. Like the abnormal pituitary morphology in the other children, these genetic findings support the true nature of the $\mathrm{CeH}$ in these 2 children.

Major strengths of our study are the large sample size $(n=456)$, the high percentage of participating children and parents $(74.8 \%)$, and the fact that we were able to recruit participants from a complete, national cohort of children with GH treatment for apparent isolated GHD over a period of 10 years. However, our study has some limitations. Firstly, diagnosing $\mathrm{CeH}$ is not easy. Although a (very) low FT4 in combination with a normal TSH concentration in the absence of nonthyroidal illness is strongly suggestive of this condition, FT4 concentrations around the lower limit of the reference interval are often difficult to interpret $[27,28]$. In addition, the decision to start LT4 treatment in the GH-treated children were made by different pediatric endocrinologists and pediatricians, using different FT4 assays and reference intervals. This may have resulted in over- as well as underestimation of the number of $\mathrm{CeH}$ cases. Furthermore, the dataset unfortunately was not complete. Not all children with isolated GHD underwent MRI of the pituitary region. This may have led to over- or underestimation of the number of children with abnormal pituitary morphology. Lastly, neonatal $\mathrm{CH}$ screening results were retrieved in only $50 \%$ of the included children, and one third had to be excluded from further analyses. This clearly affects the validity of the conclusions.

In summary, in this large retrospective cohort study, $\mathrm{CeH}$ was diagnosed in at least $6.3 \%$ of children with $\mathrm{GH}$ treatment for apparent isolated GHD. Approximately $75 \%$ of these children had congenital structural pituitary abnormalities. The same percentage of pituitary abnormalities was found in children with a low or low normal FT4 concentration, not yet diagnosed with $\mathrm{CeH}$. These findings suggest that low FT4 concentrations around the initiation of GH treatment in children with congenital GHD are a predictor of the presence of congenital structural pituitary abnormalities and, with that, the diagnosis MPHD. FT4 concentrations around the lower limit of the reference interval before $\mathrm{GH}$ treatment may indicate $\mathrm{CeH}$ and require close follow-up and, if necessary, additional diagnostic testing. Although we concur that brain imaging should be performed in every child with apparent isolated GHD, this may be postponed until a later age if FT4 concentrations are repeatedly above the lower tertile of the reference interval, and if periodic adrenal axis testing is normal. Obvious exceptions are children suspected of having a space-occupying brain lesion. Although our results suggest that children diagnosed with $\mathrm{CeH}$ around the initiation of GH treatment already had (mild) $\mathrm{CeH}$ in the neonatal period, this needs further investigation.

\section{Acknowledgments}

We acknowledge the National Institute for Public Health and the Environment (RIVM), Service for Vaccine Supply and Prevention Programs (DVP), The Netherlands.

The pediatric endocrinologists and pediatricians who contributed to this study: Dr. E.L.T. van den Akker, Dr. S.E. Barten, Dr. G. Bocca, Dr. A.E. Brandsma, Dr. A. Clement-De Boers, Drs. M. Fick, Dr. W.J.M. Gerver, Dr. K. Haasnoot, Dr. J.J.G. HoorwegNijman, Dr. G.A.P.T. Hurkx, Dr. G.A. Kamp, Dr. H.C. Kraakman, Dr. L. Lunshof, Dr. C.B. Meijssen, Dr. E.G.A.H. van Mil, Dr. P.W.J. van Mossevelde, Dr. J. Mourmans, Dr. F.S.M. Neijens, Prof. Dr. C. Noordam, Dr. R.J.H. Odink, Dr. W. Oostdijk, Dr. P.C. Overberg, Dr. E. van Pinxteren-Nagler, Dr. J.J.B. Rehbock, Dr. G. Roosendaal, Dr. T.C.J. Sas, Dr. J.J. Schermer-Rotte, Dr. D.A. Schott, Dr. E.J. Schroor, Dr. T.W. Slok, Dr. E.J. Sulkers, Dr. A.A. Verrijn Stuart, Dr. F.G.A. Versteegh, Dr. P.G. Voorhoeve, Dr. W.J. de Waal, Dr. M.J.E. Walenkamp, Dr. T. Wiersma, Dr. C.A.M. van Wijk, Dr. A. Zlotkowski, Dr. F.M. Zwaga-Nooren.

\section{Disclosure Statement}

The authors declare no conflict of interest.

\section{References}

1 Plotnick L, Rapaport R, Desrosiers P, Fuqua JS: Update from the GHMonitorSM observational registry in children treated with recombinant human growth hormone (Saizen). Pediatr Endocrinol Rev 2009;6(suppl 2): 278-282.

2 Kirk J: Indications for growth hormone therapy in children. Arch Dis Child 2012;97: 63-68.
3 National Institute of Health and Clinical Evidence: Guidance on the Use of Human Growth Hormone (Somatropin) in Children with Growth Failure. Technology Appraisal Guidance No. 188. 2010. http://www.nice. org.uk (accessed January 12, 2011).

4 Behan LA, Monson JP, Agha A: The interaction between growth hormone and the thyroid axis in hypopituitary patients. Clin Endocrinol (Oxf) 2011;74:281-288. 
5 Grunfeld C, Sherman BM, Cavalieri RR: The acute effects of human growth hormone administration on thyroid function in normal men. J Clin Endocrinol Metab 1988;67:11111114.

6 Jorgensen JO, Pedersen SB, Borglum J, Moller N, Schmitz O, Christiansen JS, Richelsen B: Fuel metabolism, energy expenditure, and thyroid function in growth hormone-treated obese women: a double-blind placebo-controlled study. Metabolism 1994;43:872-877.

7 Susperreguy S, Miras MB, Montesinos MM, Mascanfroni ID, Munoz L, Sobrero G, Silvano L, Masini-Repiso AM, Coleoni AH, Targovnik HM, Pellizas CG: Growth hormone (GH) treatment reduces peripheral thyroid hormone action in girls with Turner syndrome. Clin Endocrinol 2007;67:629-636.

8 Oliner L, Ballantine JJ: Effect of human growth hormone on thyroidal secretion, radiothyroxine turnover and transport in man. J Clin Endocrinol Metab 1968;28:603-607.

9 Rose SR, Leong GM, Yanovski JA, Blum D, Heavner G, Barnes KM, Chipman JJ, Dichek HL, Jacobsen J, Klein KE, et al: Thyroid function in non-growth hormone-deficient short children during a placebo-controlled double blind trial of recombinant growth hormone therapy. J Clin Endocrinol Metab 1995;80: 320-324.

10 Persani L: Clinical review: central hypothyroidism: pathogenic, diagnostic, and therapeutic challenges. J Clin Endocrinol Metab 2012;97:3068-3078.

11 Lippe BM, Van Herle AJ, LaFranchi SH, Uller RP, Lavin N, Kaplan SA: Reversible hypothyroidism in growth hormone-deficient children treated with human growth hormone. J Clin Endocrinol Metab 1975;40:612-618.

12 Agha A, Walker D, Perry L, Drake WM, Chew SL, Jenkins PJ, Grossman AB, Monson JP: Unmasking of central hypothyroidism following growth hormone replacement in adult hypopituitary patients. Clin Endocrinol 2007; 66:72-77.

13 Porretti S, Giavoli C, Ronchi C, Lombardi G, Zaccaria M, Valle D, Arosio M, Beck-Peccoz P: Recombinant human GH replacement therapy and thyroid function in a large group of adult GH-deficient patients: when does L-T(4) therapy become mandatory? J Clin Endocrinol Metab 2002;87:2042-2045.

14 Losa M, Scavini M, Gatti E, Rossini A, Madaschi S, Formenti I, Caumo A, Stidley CA, Lanzi R: Long-term effects of growth hormone replacement therapy on thyroid function in adults with growth hormone deficiency. Thyroid 2008;18:1249-1254.

15 Pampanini V, Pedicelli S, Gubinelli J, Scire G, Cappa M, Boscherini B, Cianfarani S: Brain magnetic resonance imaging as first-line investigation for growth hormone deficiency diagnosis in early childhood. Horm Res Paediatr 2015;84:323-330.

16 Lanting CI, van Tijn DA, Loeber JG, Vulsma T, de Vijlder JJ, Verkerk PH: Clinical effectiveness and cost-effectiveness of the use of the thyroxine/thyroxine-binding globulin ratio to detect congenital hypothyroidism of thyroidal and central origin in a neonatal screening program. Pediatrics 2005;116:168-173.

17 van Tijn DA, de Vijlder JJ, Verbeeten B Jr, Verkerk PH, Vulsma T: Neonatal detection of congenital hypothyroidism of central origin. J Clin Endocrinol Metab 2005;90:3350-3359.

18 Treatment of short stature in children with GHD. Guidelines of the Growth Hormone Advisory Board of the Dutch Society for Paediatrics. 2012.

19 Yamada M, Mori M: Mechanisms related to the pathophysiology and management of central hypothyroidism. Nat Clin Pract Endocrinol Metab 2008;4:683-694.

20 Seminara S, Stagi S, Candura L, Scrivano M, Lenzi L, Nanni L, Pagliai F, Chiarelli F: Changes of thyroid function during longterm hGH therapy in GHD children. A possible relationship with catch-up growth? Horm Metab Res 2005;37:751-756.

21 Kempers MJ, Lanting CI, van Heijst AF, van Trotsenburg AS, Wiedijk BM, de Vijlder JJ, Vulsma T: Neonatal screening for congenital hypothyroidism based on thyroxine, thyrotropin, and thyroxine-binding globulin measurement: potentials and pitfalls. J Clin Endocrinol Metab 2006;91:3370-3376.
22 Portes ES, Oliveira JH, MacCagnan P, Abucham J: Changes in serum thyroid hormones levels and their mechanisms during longterm growth hormone (GH) replacement therapy in GH deficient children. Clin Endocrinol (Oxf) 2000;53:183-189.

23 Giavoli C, Porretti S, Ferrante E, Cappiello V, Ronchi CL, Travaglini P, Epaminonda P, Arosio M, Beck-Peccoz P: Recombinant hGH replacement therapy and the hypothalamuspituitary-thyroid axis in children with GH deficiency: when should we be concerned about the occurrence of central hypothyroidism? Clin Endocrinol (Oxf) 2003;59:806-810.

24 Sun Y, Bak B, Schoenmakers N, van Trotsenburg AS, Oostdijk W, Voshol P, Cambridge E, White JK, le Tissier P, Gharavy SN, MartinezBarbera JP, Stokvis-Brantsma WH, Vulsma T, Kempers MJ, Persani L, Campi I, Bonomi M, Beck-Peccoz P, Zhu H, Davis TM, HokkenKoelega AC, Del Blanco DG, Rangasami JJ, Ruivenkamp CA, Laros JF, Kriek M, Kant SG, Bosch CA, Biermasz NR, Appelman-Dijkstra NM, Corssmit EP, Hovens GC, Pereira AM, den Dunnen JT, Wade MG, Breuning MH, Hennekam RC, Chatterjee K, Dattani MT, Wit JM, Bernard DJ: Loss-of-function mutations in IGSF1 cause an X-linked syndrome of central hypothyroidism and testicular enlargement. Nat Genet 2012;44:1375-1381.

25 Joustra SD, van Trotsenburg AS, Sun Y, Losekoot M, Bernard DJ, Biermasz NR, Oostdijk W, Wit JM: IGSF1 deficiency syndrome: a newly uncovered endocrinopathy. Rare Dis 2013;1:e24883.

26 Tatsumi K, Miyai K, Notomi T, Kaibe K, Amino N, Mizuno Y, Kohno H: Cretinism with combined hormone deficiency caused by a mutation in the PIT1 gene. Nat Genet 1992;1: 56-58.

27 Schoenmakers N, Alatzoglou KS, Chatterjee VK, Dattani MT: Recent advances in central congenital hypothyroidism. J Endocrinol 2015;227:R51-R71.

28 Fliers E, Boelen A, van Trotsenburg AS: Central regulation of the hypothalamo-pituitarythyroid (HPT) axis: focus on clinical aspects. Handb Clin Neurol 2014;124:127-138. 